\title{
Hormone replacement treatment choices in complete androgen \\ insensitivity syndrome: an audit of an adult clinic
}

\author{
Jennifer K Y Ko, Thomas F J King, Louise Williams, Sarah M Creighton and \\ Gerard S Conway \\ Department of Women's Health, University College London Hospital, London, UK
}

Correspondence

should be addressed

to G S Conway

Email

g.conway@ucl.ac.uk

\begin{abstract}
Objective: To review the treatment choices of women with complete androgen insensitivity syndrome (CAIS) at a single tertiary centre.

Design: Retrospective review.

Patients: Women with CAIS identified from our database.

Results: The study group comprised 141 women with CAIS. Eleven percent (16/141) of women had gonads in situ, 3 of whom were under workup for gonadectomy. The age of gonadectomy in the remainder 125 women was $17(0.1-53)$ years. The most common form of HRT was oral oestrogen or transdermal oestrogen in $80 \%$ (113/141). 13/141 $(9 \%)$ women used vaginal oestrogens alone or together with other forms of HRT. Testosterone preparations had been used by $17 \%$ (24/141) of women and were currently used in $10 \%(14 / 141)$. Of those who had used testosterone, $42 \%(10 / 24)$ had chosen not to continue after a therapeutic trial.

Conclusions: In a clinic offering individualised multidisciplinary care for women with CAIS, we found that the majority of women chose oestrogen-based treatment while a significant minority used testosterone.
\end{abstract}

\section{Key Words}

- hormone replacement therapy

- complete androgen insensitivity syndrome

\section{Introduction}

Complete androgen insensitivity syndrome (CAIS) is one of the most common disorders of sex development (DSD) caused by mutations of the androgen receptor gene. The estimated prevalence of AIS is 4.1 per 100,000 live born females (1). Testes develop in the presence of the $\mathrm{Y}$ chromosome, but the lack of androgen receptor activity results in a typical female phenotype. The anti-Mullerian hormone produced by the gonads causes regression of the uterus, cervix and proximal vagina during foetal development. Common clinical presentations include inguinal or labial hernia in childhood or primary amenorrhoea in adolescence (1). CAIS may also present through screening after a family member is affected or discordance between prenatal sex prediction and phenotype at birth (1).

Traditionally, prophylactic gonadectomy has been advised because of the risk of malignancy of the intraabdominal testes, which ranges from 0 to $30 \%$ (2). Current practice is to recommend gonadectomy after completion of puberty (2). Hormone replacement therapy (HRT) is required after gonadectomy in order to maintain secondary sexual characteristics, bone and cardiovascular health and to promote general wellbeing and sexual function. In the study by Berglund and coworkers, 64/78 women with AIS were on HRT and the median age at first prescription of HRT was 14 years (1). Sex steroid
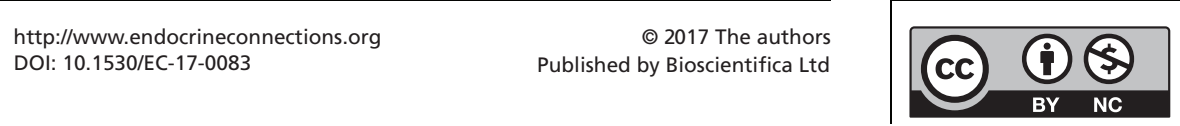

This work is licensed under a Creative Commons Attribution-NonCommercial 4.0 International License. 
replacement has traditionally been based on types of oestrogen, but there is increasing interest from user groups in the use of testosterone, which in this situation is used as a prohormone providing oestradiol via aromatisation. As women with CAIS do not have a uterus, progesterone is not required.

Based on our clinical experience, interest in the use of testosterone in women with CAIS has developed through observations voiced from user groups, particularly women who experienced late gonadectomy. Unlike younger age groups, those who have gained a sense of a 'testosterone milieu' after gonadarche are in a good position to make a comparison with a post-gonadectomy 'oestrogen milieu'. The reported differences between these two situations include altered vitality, libido and athletic performance. Of course, the psychosocial effects of a difficult diagnosis, which often coincides with gonadectomy, may contribute to such symptoms, and it is accepted that wellbeing is not solely hormone related.

As there are no known adverse effects of long-term exposure to testosterone in women with CAIS who have declined gonadectomy and in the absence of guidelines on the most appropriate HRT for this group of women, our clinic philosophy has been to offer choice and follow individual preference. Here, we reviewed our experience on HRT choices made by women with CAIS.

\section{Subjects and methods}

The study was a retrospective analysis of women with CAIS seen at the University College London Hospital (UCLH), a tertiary referral centre for DSD. Management is by a multidisciplinary team comprising an endocrinologist, gynaecologist, nurse specialist and clinical psychologist. The clinical diagnosis of CAIS was based on an unambiguous female phenotype, scant body hair, 46,XY karyotype, testicular histology and absent uterus (3). Androgen receptor mutation testing was not performed routinely when the clinical diagnosis was clearcut and only performed if the carrier status of sisters was in question. Women were followed up every 2-6 months at the start of hormonal therapy, and the follow-up spaced out to annual visits when stable. Side effects were asked at the clinic visits and information of their HRT was input into our database.

Oestrogen replacement options in the United Kingdom favour the use of oestradiol valerate or alternative esters. Conjugated equine oestrogens are gradually being phased out because of the increased risk of thrombosis (4). Oestradiol implants are not widely available in the United Kingdom.

Commonly available option for testosterone therapy in the United Kingdom includes 2\% transdermal gel (Tostran), two intramuscular options testosterone propionate $250 \mathrm{mg}$ three weekly (Sustanon) and testosterone undecanoate $1000 \mathrm{mg}$ every 12 weeks (Nebido). Oral testosterone undecanoate $40 \mathrm{mg}$ (Restandol) has recently become unavailable in the United Kingdom. The clinic protocol for testosterone replacement is to initiate with transdermal or lowdose injectable forms in combination with oestrogen before gradually progressing to testosterone only doses equivalent of those used in hypogonadal men.

Of the 154 women with CAIS who have attended the clinics at UCLH, consent for data analysis and adequate HRT data were available in 141 (92\%). Data extracted included demographics, presentation, age of gonadectomy and historical details of their HRT. Ethical approval by the Chelsea and Westminster Ethics Committee was obtained to review our dataset of medical and psychosocial outcomes in disorders of reproductive development (Integrated Research Application System number 184846). Data are presented as median (range).

\section{Results}

For the 141 women with CAIS in the study group, the median age of the women at their last attendance was 32 (16-69) years and age of diagnosis was 16 (0-38) years. The most common reason for diagnosis was primary amenorrhoea in $54 \%$ followed by hernia in childhood (29\%) and family history of CAIS (16\%). One woman presented with discordance in amniocentesis karyotype and birth phenotype. Past history of hernia was present in 59\%, which was identified at age 1.5 (0.1-24) years. Gonadectomy had been deferred indefinitely $(n=13)$ or was pending $(n=3)$ in $16 / 141(11 \%)$. In the remainder, the age of gonadectomy was $17(0.1-53)$ years.

The median age of initiation of HRT was $18(8-41)$ years. Table 1 shows the HRT choices of the 141 women of whom 23 did not require HRT either because gonads were in situ or they had chosen to stop HRT either because of intolerance or because it was age appropriate. The most common form of HRT was some form of oestrogen in $113 / 141(80 \%)$ of the total group or $96 \%$ or those requiring HRT. Vaginal oestrogens alone $(n=1)$ or together http://www.endocrineconnections.org
DOI: 10.1530/EC-17-0083
() 2017 The authors Published by Bioscientifica Ltd
This work is licensed under a Creative Commons Attribution-NonCommercial 4.0 International License. 
Table 1 Treatment choices of 141 women with CAIS.

\begin{tabular}{lrrr}
\hline Type of HRT & $\boldsymbol{n}$ & $\%$ \\
\hline Oestrogen & 113 & & 80 \\
$\quad$ Oral & & & \\
$\quad$ Oestradiol valerate & 12 & \\
$\quad$ Conjugated equine oestrogen & & & \\
Transdermal oestradiol & 13 & \\
$\quad$ Vaginal oestradiol & 3 & \\
Oestradiol implant & 14 & \\
Testosterone & 6 & \\
$\quad$ Transdermal testosterone & 6 & \\
Intramuscular testosterone & 2 & \\
$\quad$ Oral testosterone & & \\
\hline
\end{tabular}

Dose range

\author{
$1-6 \mathrm{mg} / 24 \mathrm{~h}$ \\ $0.2-1.875 \mathrm{mg} / 24 \mathrm{~h}$
}

$25-300 \mu \mathrm{g} / 24 \mathrm{~h}$

Testosterone $2 \%$ gel

Testosterone undecanoate $1000 \mathrm{mg}$ every $10-12$ weeks Testosterone propionate $125-250 \mathrm{mg}$ every $1-4$ weeks Testosterone undecanoate $40-120 \mathrm{mg}$

Note that each entry is not mutually exclusive with three individuals using combined oral and transdermal oestrogen, 12 women using vaginal oestrogen as a supplement to other sources and 8 using combined oestrogen and testosterone. With regard to testosterone, 5 women on transdermal and one on intramuscular used concurrent oestrogen.

with systemic sex steroids $(n=12)$ were required in $13 / 141$ (9\%) women.

Testosterone was used in 14/141 (10\%) of the total group or $12 \%$ of women requiring HRT with 8 women choosing to combine both oestrogen and testosterone treatments and 6 using testosterone alone. The median duration of use of testosterone was 4 (1-25) years. Most notable was an individual who used Nebido at full dose for 25 years with no side effects and well-maintained vitality. On review of past HRT experience, a further 10 individuals had used testosterone therapy in the past but had discontinued. The reason for discontinuing was almost universally that no meaningful benefit was perceived. No side effects to testosterone were recorded in routine clinic notes. Overall, therefore 24 (17\%) women had used testosterone therapy at some time.

\section{Discussion}

This study is the first to provide real-life data on the hormone treatment choices made by adult women with CAIS. Oestrogen was used by $96 \%$ of those using HRT and testosterone by $12 \%$. Over half (58\%) of women who had tried testosterone treatment chose to continue at the time of assessment.

The most common form of HRT in our study was oral oestrogen, followed by transdermal oestrogen. Advantages of transdermal over oral oestrogen formulations are well known, including a more physiologic mode of delivery, decrease hepatic first-pass effect and reduced risk of thromboembolism, but oral oestrogen is widely accepted by patients owing to the convenience of administration $(5,6)$. The dosage used was based empirically on clinical wellbeing reported by the patient. Individuals were offered a dose adjustment at each clinic visit with physician guidance and with reference to the bone mineral density (BMD) measurement. To assist women in making the decision, they are informed of their BMD result and the general rule was the higher dose of HRT of any kind is a benefit to bone density $(7,8)$. Local vaginal oestrogen was used by $9 \%$ of women, often prescribed as adjuvant therapy for those who require vaginal dilatation. Oestrogen implants were previously a popular choice but only a few users remained on implants at the time of this assessment as this form of treatment is not easily available in the United Kingdom.

A proportion of women with CAIS favoured the use of testosterone. This group of women were often previous users of oestrogen implants, which were an ideal option for women without a uterus who required an implant only every six months, eliminating the need for daily treatment. Intramuscular depot preparation of testosterone is a useful alternative requiring only 4 injections per year. In a small double-blind crossover study, there was no difference in psychosexual functioning in 4 women with CAIS using either androgen or oestrogen therapy for 4 weeks (9). A trial comparing the clinical and metabolic effects of testosterone and oestradiol in adult gonadectomised patients with $46, \mathrm{XY}$ DSD due to CAIS is underway but results are not available yet (10). Our clinic experience leads us to conclude that controlled trials comparing oestrogen and testosterone would be extremely difficult because of the subtlety and imprecise quantification of outcome measures and because of the difficulty of blinding suitably high-dose preparations.

In a study among forty six 46,XY subjects with DSD, only $47.8 \%$ had an accurate diagnosis (11). With

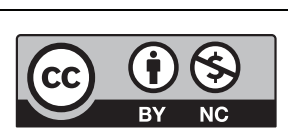

This work is licensed under a Creative Commons Attribution-NonCommercial 4.0 International License. 
this is mind, one point of caution when considering testosterone replacement is that some women with CAIS, particularly those with gonadectomy before 15 years of age, may be testosterone sensitive as mutations of steroid 5-alpha-reductase 1 (SRD5A1) or hydroxysteroid 17-beta dehydrogenase 3 (HSD17B3) can mimic CAIS on occasion. If an individual has not had sufficient exposure to endogenous testosterone, then we favour starting testosterone at low dose for several months. Some features of virilisation such as voice change are irreversible. For women who have been exposed to endogenous testosterone by virtue of late gonadectomy, then intramuscular depot preparations of testosterone can be commenced directly.

In general, HRT should be administered until the age of natural menopause, although extended use with monitoring of BMD at regular intervals can be considered in women with low BMD in the absence of contraindications. Low BMD has been reported in women with CAIS owing to low circulating oestrogen before gonadectomy or inadequate oestrogen replacement after gonadectomy (12). The relatively tall stature of CAIS who had late gonadectomy has been interpreted as possible evidence of oestrogen deficiency (13). Mizunuma demonstrated a drop in BMD after gonadectomy in 2 subjects with CAIS, followed by an increase after treatment with oestrogens (14). Women who had good compliance with oestrogen replacement therapy had significantly better bone density compared to those who reported poor compliance (15). In a separate report, we explored the relationship between age of gonadectomy and bone density in a subgroup of this cohort (16). It is beyond the scope of this paper to address long-term morbidity and mortality, which would require a much larger study group and follow-up time. Long-term outcomes might have to be taken into account in the future as more information becomes available.

In conclusion, we present the real-life experience of women attending a clinic for adults with CAIS in making choices for HRT. These observations illustrate a personalised approach to care. For many women with CAIS, routine oestrogen replacement as for any other form of hypogonadism is appropriate. At each visit, a review of wellbeing is undertaken, and alternative is considered if shortcomings are identified. While the majority of women with CAIS choose oestrogen-based treatment after gonadectomy, a significant minority prefer testosterone and our experience is that this is a satisfactory option. Even though no formal safety data are available for the use of testosterone in CAIS, we could identify no theoretical or practical reason not to offer this option.

\section{Declaration of interest}

The authors declare that there is no conflict of interest that could be perceived as prejudicing the impartiality of the research reported.

\section{Funding}

This research did not receive any specific grant from any funding agency in the public, commercial or not-for-profit sector.

\section{References}

1 Berglund A, Johannsen TH, Stochholm K, Viuff MH, Fedder J, Main KM \& Gravholt $\mathrm{CH}$. Incidence, prevalence, diagnostic delay, and clinical presentation of female $46, \mathrm{XY}$ disorders of sex development. Journal of Clinical Endocrinology and Metabolism 2016 101 4532-4540. (doi:10.1210/jc.2016-2248)

2 Patel V, Casey RK \& Gomez-Lobo V. Timing of gonadectomy in patients with complete androgen insensitivity syndrome-current recommendations and future directions. Journal of Pediatric and Adolescent Gynecology 201629 320-325. (doi:10.1016/j. jpag.2015.03.011)

3 Quigley CA, De Bellis A, Marschke KB, el-Awady MK, Wilson EM $\&$ French FS. Androgen receptor defects: historical, clinical, and molecular perspectives. Endocrine Reviews 199516 271-321. (doi:10.1210/edrv-16-3-271)

4 Smith NL, Heckbert SR, Lemaitre RN, Reiner AP, Lumley T, Weiss NS, Larson EB, Rosendaal FR \& Psaty BM. Esterified estrogens and conjugated equine estrogens and the risk of venous thrombosis. JAMA 2004292 1581-1587. (doi:10.1001/jama.292.13.1581)

5 Stevenson JC. Type and route of estrogen administration. Climacteric 200912 (Supplement 1) 86-90. (doi:10.1080/13697130903007389)

6 POI Guideline Development Group. ESHRE guideline. Management of women with premature ovarian insufficiency. December 2015 Grimbergen, Belgium: ESHRE, 2015. (available at: https://www.eshre eu/Guidelines-and-Legal/Guidelines/Management-of-prematureovarian-insufficiency.aspx)

7 Horsman A, Jones M, Francis R \& Nordin C. The effect of estrogen dose on postmenopausal bone loss. New England Journal of Medicine 1983309 1405-1407. (doi:10.1056/NEJM198312083092301)

8 Boivin G, Vedi S, Purdie DW, Compston JE \& Meunier PJ. Influence of estrogen therapy at conventional and high doses on the degree of mineralization of iliac bone tissue: a quantitative microradiographic analysis in postmenopausal women. Bone 200536 562-567. (doi:10.1016/j.bone.2004.12.009)

9 Slob AK, van der Werff ten Bosch JJ, van Hall EV, de Jong FH, Weijmar Schultz WC \& Eikelboom FA. Psychosexual functioning in women with complete testicular feminization: is androgen replacement therapy preferable to estrogen? Journal of Sex and Marital Therapy 199319 201-209. (doi:10.1080/00926239308404905)

10 Birnbaum W, Marshall L, Schnabel D, Balspratch M, Richter-Unruh A, Wagner R, Kropf S \& Hiort O. Comparison of clinical and metabolic effect of testosterone and estradiol in adult gonadectomized patients with 46 XY DSD due to complete androgen insensitivity (abstract). In 3rd International Symposium on Disorder of Sex Development, p71. Lubeck, May 20-22, 2011.

11 Minto CL, Crouch NS, Conway GS \& Creighton SM. XY females: revisiting the diagnosis. British Journal of Obstetrics and Gynaecology 2005112 1407-1410. (doi:10.1111/j.1471-0528.2005.00664.x)
This work is licensed under a Creative Commons Attribution-NonCommercial 4.0 International License. 
12 Soule SG, Conway G, Prelevic GM, Prentice M, Ginsburg J $\&$ Jacobs HS. Osteopenia as a feature of the androgen insensitivity syndrome. Clinical Endocrinology 199543 671-675. (doi:10.1111/j.1365-2265.1995.tb00533.x)

13 Han TS, Goswami D, Trikudanathan S, Creighton SM \& Conway GS Comparison of bone mineral density and body proportions between women with complete androgen insensitivity syndrome and women with gonadal dysgenesis. European Journal of Endocrinology 2008159 179-185. (doi:10.1530/EJE-08-0166)

14 Mizunuma H, Soda M, Okano H, Kagami I, Miyamoto S, Ohsawa M \& Ibuki Y. Changes in bone mineral density after orchidectomy and hormone replacement therapy in individuals with androgen insensitivity syndrome. Human Reproduction 199813 2816-2818. (doi:10.1093/humrep/13.10.2816)

15 Marcus R, Leary D, Schneider DL, Shane E, Favus M \& Quigley CA The contribution of testosterone to skeletal development and maintenance: lessons from the androgen insensitivity syndrome. Journal of Clinical Endocrinology and Metabolism 200085 1032-1037. (doi:10.1210/jcem.85.3.6428)

16 King TFJ, Wat WZM, Creighton SM \& Conway GS. Bone mineral density in complete androgen insensitivity syndrome and the timing of gonadectomy. Clinical Endocrinology 2017 [in press].

Received in final form 12 June 2017

Accepted 14 June 2017

Accepted Preprint published online 14 June 2017 http://www.endocrineconnections.org DOI: 10.1530/EC-17-0083
(C) 2017 The authors Published by Bioscientifica Ltd

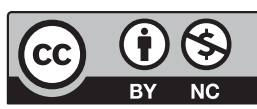

This work is licensed under a Creative Commons Attribution-NonCommercial 4.0 International License. 